Donk, C.F.M. van der, Rijnders, M.I.A., Donker, G.A., Neeling, A.J. de, Nys, S., Stobberingh, E.Ef Is living in a border region a risk for a high prevalence of resistance? European Journal of

\begin{tabular}{|l|l|}
\hline $\begin{array}{l}\text { Postprint } \\
\text { Version }\end{array}$ & 1.0 \\
\hline Journal website & http://link.springer.com/article/10.1007/s10096-013-1835-7 \\
\hline Pubmed link & $\underline{\text { http://www.ncbi.nlm.nih.gov/pubmed/23397234 }}$ \\
\hline DOI & $10.1007 /$ s10096-013-1835-7 \\
\hline
\end{tabular}

This is a NIVEL certified Post Print, more info at http://www.nivel.eu

\title{
Is living in a border region a risk for a high prevalence of resistance?
}

C. F. M. VAN DER DONK ${ }^{1,2}$, M. I. A. RIJNDERS ${ }^{1,3}$, G. A. DONKER ${ }^{4}$, A. J. DE NEELING ${ }^{5}$, S. $\mathrm{NYS}^{1,6}$ AND E. E. STOBBERINGH ${ }^{1,2,7}$

${ }^{(1)}$ Department of Medical Microbiology, Maastricht University Medical Centre, P. Debyelaan 25, 6229 HX Maastricht, The Netherlands

(2) CAPHRI School for Public Health and Primary Care, Maastricht University,

Universiteitssingel 50, 6229 ER Maastricht, The Netherlands

${ }^{(3)}$ Department of Internal Medicine, Atrium Medical Centre, Henri Dunantstraat 5, 6419 PC

Heerlen, The Netherlands

(4) NIVEL, Netherlands Institute for Health Services Research, Otterstraat 118, 3513 CR

Utrecht, The Netherlands

${ }^{(5)}$ Centre for Infectious Disease Control, National Institute for Public Health and the Environment (RIVM), Antonie van Leeuwenhoeklaan 9, 3721 MA Bilthoven, The Netherlands

(6) Department of Clinical Biology, Jessa Hospital, Stadsomvaart 11, 3500 Hasselt, Belgium

(7) Department of Medical Microbiology, Maastricht University Medical Centre, P.O. Box 5800, 6202 AZ Maastricht, The Netherlands

\begin{abstract}
This study assessed the antimicrobial resistance and population structure of Staphylococcus aureus isolated from general practice (GP) patients and nursing home $(\mathrm{NH})$ residents in the province of Limburg (near the border with Germany and Belgium) in comparison with those obtained in the remaining provinces of the Netherlands. A total of 617 and $418 \mathrm{~S}$. aureus isolates were isolated from 2,691 to 1,351 nasal swabs from GP patients and NH residents, respectively. Quantitative antibiotic susceptibility testing was performed using a microbroth dilution method. Putative methicillin-resistant S. aureus (MRSA) isolates were tested for the presence of the mecA gene and spa typing was performed on all S. aureus isolates. No significant differences in the prevalence of resistance were found between the two groups of GP isolates, but the isolates from the $\mathrm{NH}$ residents showed a lower resistance for trimethoprim-sulfamethoxazole $(\mathrm{p}=$ 0.003) in Limburg province compared with the remaining provinces in the Netherlands. Among the isolates from NH residents in Limburg province, the prevalence of spa-CC 084 was higher $(p=0.003)$ and that of spa-CC 002 was lower $(\mathrm{p}=0.01)$ compared with isolates from NHs in the remaining provinces of the Netherlands. We observed no differences in resistance and population
\end{abstract}


Donk, C.F.M. van der, Rijnders, M.I.A., Donker, G.A., Neeling, A.J. de, Nys, S., Stobberingh, E.Ef Is living in a border region a risk for a high prevalence of resistance? European Journal of Clinical Microbiology \& Infectious Diseases: 2013, 32(8), 989-995

structure between S. aureus isolates from GP patients in Limburg and the remaining provinces of the Netherlands, and only a few differences were observed between the $\mathrm{NH}$ populations. There was no higher prevalence of resistance among the GP and $\mathrm{NH}$ isolates from Limburg compared with the remaining provinces.

\section{INTRODUCTION}

Staphylococcus aureus is a frequent causative agent of community- and hospitalacquired infections, varying from minor skin and soft tissue infections to invasive infections like bacteremia and endocarditis ${ }^{[1]}$. In many European countries, the antibiotic resistance of S. aureus is increasing ${ }^{[2]}$ and, consequently, an optimal empiric antibiotic choice for the treatment of S. aureus infections becomes more challenging. In particular, the prevalence of methicillin-resistant S. aureus (MRSA) is a point of concern. In the Netherlands, the prevalence of MRSA is still low ${ }^{[3]}$, which can, at least in part, be attributed to the national antibiotic policy and the infection control guidelines (including the "search and destroy" protocol). However, in recent years, several reports have mentioned MRSA outbreaks in Dutch nursing homes $(\mathrm{NHs}){ }^{[4}{ }^{7]}$.

The prevalence of antibiotic resistance and MRSA is higher in Belgium and Germany than in the Netherlands ${ }^{[2]}$, with a prevalence of MRSA in hospitals of 20.5 $\%, 20.9 \%$, and $1.2 \%$, respectively ${ }^{[2]}$. The province of Limburg has a border with Belgium and Germany of $351 \mathrm{~km}$ and a border with two other Dutch provinces (i.e., Noord-Brabant and Gelderland) of only $113 \mathrm{~km}^{[8]}$, and is a region with intensive cross-border traffic ( $4 \%$ of all jobs in Limburg is fulfilled by Belgian and German citizens) and cross-border patient mobility due to the (free) access to health care facilities on both sides of the border ${ }^{[9}{ }^{11]}$.

There is no information available as to whether residents of the province of Limburg, due to its location, have a higher prevalence of resistance among S. aureus isolates and whether these isolates have a different population structure than those in the remaining provinces of the Netherlands. Therefore, we evaluated the antibiotic resistance and population structure of S. aureus isolates from general practice (GP) patients and $\mathrm{NH}$ residents in the province of Limburg in comparison with those of the remaining provinces of the Netherlands.

\section{METHODS}

\section{Study population and isolation of S. aureus}

In 2005, a total of 2,691 nasal swabs (Amies agar gel swabs without charcoal 108C, Copan Diagnostics, Brescia, Italy) were taken from the anterior nostrils from GP patients with no apparent signs of infection from ten GPs in Limburg province (GPL) and 19 GPs in the remaining provinces in the Netherlands (GP-NL). The nasal swabs were analyzed as described previously ${ }^{[12]}$. In 2009 and 2010, a total of 1,351 nasal swabs were collected from $\mathrm{NH}$ residents from six NHs in the province of Limburg (NH-L) and from 24 NHs in other provinces of the Netherlands (NH-NL, Table 1). The swabs were analyzed with the same methods as the GP swabs ${ }^{[12]}$. Informed consent was obtained from all participants. 
Donk, C.F.M. van der, Rijnders, M.I.A., Donker, G.A., Neeling, A.J. de, Nys, S., Stobberingh, E.Ef Is living in a border region a risk for a high prevalence of resistance? European Journal of Clinical Microbiology \& Infectious Diseases: 2013, 32(8), 989-995

\section{[TABLE 1]}

\section{Quantitative susceptibility testing}

Quantitative susceptibility testing was performed using microbroth dilution with Mueller Hinton II cation-adjusted broth (Becton-Dickinson, Sparks, MD, USA) and microtiter plates with freeze-dried antibiotics (MCS Diagnostics BV, Swalmen, the Netherlands). S. aureus ATCC 29213 was used as a control strain. The breakpoints for resistance were in accordance to the European Committee on Antimicrobial Susceptibility Testing (EUCAST) ${ }^{[13]}$. Antibiotic susceptibility testing for fusidic acid and mupirocin was performed with a disk diffusion test with Mueller Hinton II agar plates (BD) and antibiotics tablets (fusidic acid $100 \mu \mathrm{g}$ and mupirocin $10 \mu \mathrm{g}$, Rosco, Taastrup, Denmark). Zone diameters of $>27 \mathrm{~mm}$ for fusidic acid and $>15 \mathrm{~mm}$ for mupirocin were considered to be susceptible ${ }^{[14},{ }^{15]}$. Oxacillin-resistant isolates were analyzed for the presence of the mecA gene using a polymerase chain reaction (PCR) assay, as described previously ${ }^{[12]}$.

\section{Typing of the spa locus}

Amplification of the spa locus, followed by sequencing, was performed as described previously ${ }^{[16,}{ }^{17]}$. The spa types were clustered into spa-clonal complexes (spa-CCs) using the Based Upon Repeat Pattern (BURP) algorithm with Ridom StaphType software version 2.2.1 (http://www.ridom.de). The spa types with $<6$ repeats were excluded from the analysis and spa types were clustered if the cost was $<5$, to prevent the formation of too large and non-specific spa clusters. After applying the BURP algorithm, the associated multilocus sequence typing (MLST) clonal complexes (CCs) were allocated through the Ridom SpaServer (http://spaserver.ridom.de).

\section{Statistical analysis}

Significant statistical differences in antibiotic resistance were calculated using the Pearson Chi-square test or a Fisher's exact test (PASW software version 18.0, IBM, Armonk, NY, USA). A modified false discovery rate (FDR) method developed by Benjamini and Yekutieli was used as the method of correction for multiple testing ${ }^{[18]}$. A p-value $<0.05$ was considered to be statistically significant. The diversity of the groups of isolates regarding the spa types was determined with Simpson's index of diversity ${ }^{[19]}$.

\section{RESULTS}

\section{Prevalence of S. aureus carriage}

The prevalence of S. aureus nasal carriage was $23 \%, 247$ isolates out of 1,096 swabs and 370 isolates out of 1,595 swabs, among both GP-L and GP-NL, respectively (Table 1). The prevalence among the NH residents was 31 \%, 100 isolates out of 291 swabs in NH-L, and $29 \%, 318$ isolates out of 1,060 swabs in NH-NL.

\section{Prevalence of antibiotic resistance}

The antibiotic susceptibility patterns of the isolates are shown in Table 2. Unfortunately, for further analysis, 22 of the S. aureus isolates could not be cultured from the frozen stock. 
Donk, C.F.M. van der, Rijnders, M.I.A., Donker, G.A., Neeling, A.J. de, Nys, S., Stobberingh, E.Ef Is living in a border region a risk for a high prevalence of resistance? European Journal of Clinical Microbiology \& Infectious Diseases: 2013, 32(8), 989-995

\section{[TABLE 2]}

No significant differences in resistance were demonstrated between GP-L and GPNL. Resistance to linezolid, trimethoprim-sulfamethoxazole, vancomycin, gentamicin, and mupirocin was either not observed or less than $1 \%$. Four isolates were resistant to oxacillin ${ }^{[}$minimum inhibitory concentration (MIC) 4 or $8 \mathrm{mg} / \mathrm{L}^{]}$, but none of these isolates harbored the mecA gene. These isolates had the following spa types: t062, t127, t224, and $\mathrm{t} 1702$.

Among the NH isolates, the prevalence of resistance was lower for trimethoprimsulfamethoxazole $(\mathrm{p}=0.003)$ and clarithromycin $(\mathrm{p}=0.093)$ from NH-L $(0 \%$ and 2 $\%$, respectively) compared with NH-NL ( $9 \%$ and $8 \%$, respectively). All but one of the trimethoprim-sulfamethoxazole-resistant isolates harbored spa t064. Six isolates (two in NH-L and four in NH-NL) were resistant to oxacillin (MIC $8 \mathrm{mg} / \mathrm{L}$ to $>64$ $\mathrm{mg} / \mathrm{L}$ ), carried the mecA gene, and had the following spa types: t002, t037, t091, t223, t740, and t2164. Resistance to vancomycin, gentamicin, mupirocin, and linezolid was either not demonstrated or less than $1 \%$.

\section{Distribution of spa types and BURP analysis}

A total of 329 spa types were found. The most prevalent spa types among all isolates were t008 (6.6 \%), t002 (5.8\%), and t091 (5.1\%). The other spa types accounted for $0.1 \%$ to $4.1 \%$ each. Among the GP-L isolates, spa types t012 (6.5\%), t091 (5.7\%), and t002 (4.0\%) were the most prevalent, and among the GP-NL isolates, spa types t091 (5.5\%), t008 (4.9\%), and t012 (4.9\%) were the most prevalent. Among the NH-L isolates, spa types t008 (22\%), t091 (10\%), and t026 (7\%) were the most prevalent, and among the NH-NL isolates, spa types t002 (9.8\%), t064 (8.2\%), and t008 (6.6 \%) were the most prevalent.

The spa types were clustered into 16 spa-CCs (Table 3). Three clusters had no founder and 33 spa types (3.3\%) could not be clustered into an spa-CC and were classified as singletons. Seventy isolates (6.9\%) were excluded from the analysis, since these spa types consisted of less than five repeats and 11 isolates were not typable.

\section{[TABLE 3]}

Overall, the percentage of isolates belonging to each spa-CC was similar for GP-L and GP-NL and for NH-L and NH-NL. The only difference observed was for the NH isolates: the prevalence of spa-CC $084(7 \%)$ was higher $(\mathrm{p}=0.003)$ and that of spaCC $002(17 \%)$ was lower $(p=0.01)$ among isolates collected from NH-L compared with those from NH-NL.

There was also variation in the diversity of the spa types among the $\mathrm{NH}$ isolates: $0.929{ }^{[} 95 \%$ confidence interval (CI) $0.896-0.962^{]}$and 0.971 (95 \% CI 0.963-0.978) for the NH-L and NH-NL isolates, respectively.

The spa types were associated to an MLST ST or CC via the Ridom SpaServer (Table 4). No significant differences were found between the GP-L and GP-NL isolates (56 \% and $61 \%$, respectively) and the NH-L and NH-NL isolates (73\% and $79 \%$, respectively) 
Donk, C.F.M. van der, Rijnders, M.I.A., Donker, G.A., Neeling, A.J. de, Nys, S., Stobberingh, E.Ef Is living in a border region a risk for a high prevalence of resistance? European Journal of Clinical Microbiology \& Infectious Diseases: 2013, 32(8), 989-995

\section{[TABLE 4]}

\section{DISCUSSION}

In this study, we observed no difference in the prevalence of resistance between the S. aureus isolates from GP-L and GP-NL, but there was a significantly lower prevalence of resistance to trimethoprim-sulfamethoxazole for the isolates from $\mathrm{NH}$ L compared with those from NH-NL. Significant differences in the prevalence of spa-CCs 084 and 002 were also found for the $\mathrm{NH}$ isolates.

The strength of the study is that all samples were analyzed at the same laboratory with the same methods. Bias due to differences in methods can, therefore, be excluded. The study also has some weaknesses: the number of NH-L isolates was lower compared to the other groups of isolates. Also, clinical data was not available and, although there was a difference in the sampling period between the GP and NH isolates, we do not expect that this could explain the differences in the prevalence of resistance observed ${ }^{[20]}$.

The $23 \%$ prevalence of nasal colonization with S. aureus among both groups of GP patients was in agreement with previous reports ${ }^{[21]}$, which also applies for the $29 \%$ and $31 \%$ prevalences among the NH resident populations. Previous studies reported prevalences in the range $23.9-43 \%{ }^{\left[22 \_24\right]}$.

No differences in antibiotic resistance were found between isolates collected from the two groups of GP patients, but between the two groups of NH residents, a difference in trimethoprim-sulfamethoxazole resistance was observed. The difference observed might be due to differences in antibiotic use. $\mathrm{NH}$ residents are a frail population, with a high use of antibiotics and more risk factors for acquiring and retaining a more resistant $\mathrm{S}$. aureus isolate ${ }^{[22},{ }^{25]}$. However, among GP patients and $\mathrm{NH}$ residents, resistance to trimethoprim-sulfamethoxazole was rare, despite their relatively high use ${ }^{[26]}$, and further studies seem warranted. The 27 resistant isolates (out of 1,013) were found in 13 different NHs and all but one harbored spa type 064, which is an spa type associated with MLST CC 8, an MRSA-associated MLST CC. Quinolone resistance was higher among the $\mathrm{NH}$ residents compared with the GP patients. Higher use of quinolones in NHs compared to GP patients is probably the main reason for the higher prevalence of resistance ${ }^{[27,}{ }^{28]}$. However, also, differences in living environment, higher age, comorbidities, and use of indwelling devices could play a role ${ }^{[23]}$.

Among the isolates from the GP patients, the four oxacillin-resistant isolates were classified as borderline oxacillin-resistant $\mathrm{S}$. aureus (BORSA). Isolates like these have been described previously, but mostly in a clinical setting ${ }^{[29}{ }^{31]}$. The clinical relevance of these isolates remains questionable.

With BURP, all spa types were allocated in spa-CCs. The only significant difference was found for spa-CC 084 and spa-CC 002 between the NH groups. Overall, spa-CC 012 was quite large and could be associated to two very different MLST CCs, i.e., CC 30 and 45. With more strict BURP settings (cost $<4$ ), this spa-CC could be divided into a few smaller clusters, of which spa-CC 012, associated to MLST CC 30, and spa-CC 015, associated to MLST CC 45, were the largest (74 \% of all isolates in this group). In line with the differences in spa-CCs, differences in the prevalence of isolates associated with an MRSA-associated MLST CC were observed. 
Donk, C.F.M. van der, Rijnders, M.I.A., Donker, G.A., Neeling, A.J. de, Nys, S., Stobberingh, E.Ef Is living in a border region a risk for a high prevalence of resistance? European Journal of Clinical Microbiology \& Infectious Diseases: 2013, 32(8), 989-995

The diversity of the spa types from the GP isolates was comparable with previous reports ${ }^{[32},{ }^{33]}$. The lower diversity of the spa types among the $\mathrm{NH}$ isolates might be due to the enclosed living environment, transmission within the NHs, and higher antibiotic use. These factors, combined with the lower number of participating NHs in Limburg, might explain the lower diversity among the NH isolates in Limburg. We observed only minor differences in antibiotic resistance and population structure between isolates collected from GP patients and NH residents in Limburg and the remaining parts of the Netherlands.

Although the differences in the prevalence of S. aureus resistance among hospital isolates from Belgium, Germany, and the Netherlands are considerable, the differences were much smaller among isolates from the extramural setting, especially among GP patients. So, living in the border region of the province of Limburg is not a risk for a high prevalence of resistance, but whether this is due to the absence of cross-border spread or only spread mostly via the extramural setting, where resistance is low, remains to be investigated.

Furthermore, this study provides an overview of S. aureus resistance and population structure among GP patients and NH residents in the Netherlands. Surveillance at a local and international level is warranted, in order to keep informed as to changes in the prevalence of resistance over time.

\section{Acknowledgments}

The authors would like to thank the participants for their help, and the general practitioners and the nursing home staff for their assistance with the collection of the samples.

\section{Funding}

This project was financially supported, in part, by the Dutch Working Party on Antibiotic Policy (SWAB) and, in part, by Provincie Limburg, the Netherlands; Ministerium für Wirtschaft, Energie, Bauen, Wohnen und Verkehr des Landes Nordrhein-Westfalen, Germany; Ministerium der Deutschsprachigen Gemeinschaft Belgiens, Belgium; Provincie Limburg, Belgium; Wallonie, Belgium; RheinlandWestfalen, Germany; Interreg and the Euregio Maas-Rijn with support of the European Fund for Regional Development (EFRO).

The funding institutions were not involved in any part of this study.

\section{Competing interests}

None to declare.

\section{Ethical approval}

Ethical approval for this project was granted by the Medical Ethics Committee of the Maastricht University Medical Centre, reference number: 07-4-012.4/pl.

\section{REFERENCES}

1.Lowy FD (1998) Staphylococcus aureus infections. N Engl J Med 339(8):520-532

2.European Centre for Disease Prevention and Control (ECDC) (2011) Antimicrobial resistance surveillance in Europe 2010. Annual report of the European Antimicrobial Resistance Surveillance Network (EARS-Net)

3.Dutch Working Party on Antibiotic Policy (SWAB) Nethmap 2011. Consumption of antimicrobial agents and antimicrobial resistance among medically important bacteria in the Netherlands 
Donk, C.F.M. van der, Rijnders, M.I.A., Donker, G.A., Neeling, A.J. de, Nys, S., Stobberingh, E.Ef Is living in a border region a risk for a high prevalence of resistance? European Journal of Clinical Microbiology \& Infectious Diseases: 2013, 32(8), 989-995

4.AT5. MRSA-uitbraak in verpleeghuis Bernardus. Available online at: http://www.at5.nl/artikelen/57488/mrsa-uitbraak-in-verpleeghuis-bernardus. Accessed 20 June 2012

5.Nursing voor verpleegkundigen. MRSA-uitbraak in verpleeghuis Delfzijl. Available online at: http://www.nursing.nl/home/nieuw/2853/mrsa-uitbraak-in-verpleeghuis-delfzijl. Accessed 20 June 2012

6.BN De Stem. MRSA-bacterie in Janshove. Available online at: http://www.bndestem.nl/regio/breda/7969474/MRSAbacterie-in-Janshove.ece. Accessed 20 June 2012

7.Omroep Flevoland. MRSA-uitbraak Laarstaete gestopt. Available online at: http://www.omroepflevoland.nl/Nieuws/31528/mrsa-uitbraak-laarstaete-gestopt. Accessed 20 June 2012

8.Provincie Limburg. Feiten en cijfers. Available online at: http://www.limburg.nl/Over_Limburg/Feiten_en_cijfers. Accessed 20 June 2012

9. Commission of the European Communities (2008) Proposal for a directive of the European parliament and the council on the application of patients' rights in cross-border healthcare. Brussels, 2.7.2008. COM(2008) 414 final

10.Vaessens RCM (2011) Limburgse pendel 2010: pendelstromen op provinciaal en gemeentelijk niveau. ETIL, Maastricht

11.Stadt Aachen. Euregion Maas-Rijn. Available online at: http://www.aachen.de/nl/sb/euregio/index.html. Accessed 20 June 2012

12.Donker GA, Deurenberg RH, Driessen C, Sebastian S, Nys S, Stobberingh EE (2009) The population structure of Staphylococcus aureus among general practice patients from The Netherlands. Clin Microbiol Infect 15(2):137-143

13.European Committee on Antimicrobial Susceptibility Testing (EUCAST) (2011) Breakpoint tables for interpretation of MICs and zone diameters. Version 1.3, January 2011 14. Fuchs PC, Jones RN, Barry AL (1990) Interpretive criteria for disk diffusion susceptibility testing of mupirocin, a topical antibiotic. J Clin Microbiol 28(3):608-609

15.Diagnostica R. EUCAST-and CLSI potency NEO-SENSITABS ${ }^{\mathrm{TM}}$. Interpretation zones and MIC breakpoints according to CLSI. Staphylococci. Document 3.3.0

16.Frénay HM, Bunschoten AE, Schouls LM, van Leeuwen WJ, Vandenbroucke-Grauls CM, Verhoef J, Mooi FR (1996) Molecular typing of methicillin-resistant Staphylococcus aureus on the basis of protein A gene polymorphism. Eur J Clin Microbiol Infect Dis 15(1):60-64

17.Schouls LM, Spalburg EC, van Luit M, Huijsdens XW, Pluister GN, van Santen-Verheuvel MG, van der Heide HG, Grundmann H, Heck ME, de Neeling AJ (2009) Multiple-locus variable number tandem repeat analysis of Staphylococcus aureus: comparison with pulsed-field gel electrophoresis and spa-typing. PLoS One 4(4):e5082

18.Narum SR (2006) Beyond Bonferroni: less conservative analyses for conservation genetics. Conserv Genet 7:783-787

19.Grundmann H, Hori S, Tanner G (2001) Determining confidence intervals when measuring genetic diversity and the discriminatory abilities of typing methods for microorganisms. J Clin Microbiol 39(11):4190-4192

20.den Heijer CDJ et al (2012) Prevalence and susceptibility of commensal S. aureus in nine European countries. In: Proceedings of the World Organization of Family Doctors Europe Conference 2012 (WONCA 2012), Vienna, Austria, July 2012

21.Wertheim HF, Vos MC, Ott A, van Belkum A, Voss A, Kluytmans JA, van Keulen PH, Vandenbroucke-Grauls CM, Meester MH, Verbrugh HA (2004) Risk and outcome of nosocomial Staphylococcus aureus bacteraemia in nasal carriers versus non-carriers. Lancet 364(9435):703-705

22.Daeschlein G, Assadian O, Rangous I, Kramer A (2006) Risk factors for Staphylococcus aureus nasal carriage in residents of three nursing homes in Germany. J Hosp Infect 63(2):216-220

23.Lasseter G, Charlett A, Lewis D, Donald I, Howell-Jones R, McNulty CA (2010) Staphylococcus aureus carriage in care homes: identification of risk factors, including the role of dementia. Epidemiol Infect 138(5):686-696

24. Karabay O, Otkun MT, Yavuz MT, Otkun M (2006) Nasal carriage of methicillin-resistant and methicillin-susceptible Staphylococcus aureus in nursing home residents in Bolu, Turkey. W Indian Med J 55(3):183-187 
Donk, C.F.M. van der, Rijnders, M.I.A., Donker, G.A., Neeling, A.J. de, Nys, S., Stobberingh, E.Ef Is living in a border region a risk for a high prevalence of resistance? European Journal of

Clinical Microbiology \& Infectious Diseases: 2013, 32(8), 989-995

25.van der Donk CFM, Schols JMGA, Driessen CJ, Hagenouw RGP, Meulendijks A, Stobberingh EE (2012) Prevalence and spread of multidrug resistant Escherichia coli isolates among nursing home residents in the southern part of the Netherlands. J Am Med Dir Assoc (in press)

26.Dutch Working Party on Antibiotic Policy (SWAB) Nethmap 2009. Consumption of antimicrobial agents and antimicrobial resistance among medically important bacteria in the Netherlands

27.Goossens H, Ferech M, Vander Stichele R, Elseviers M; ESAC Project Group (2005) Outpatient antibiotic use in Europe and association with resistance: a cross-national database study. Lancet 365(9459):579-587

28.Vellinga A, Tansey S, Hanahoe B, Bennett K, Murphy AW, Cormican M (2012) Trimethoprim and ciprofloxacin resistance and prescribing in urinary tract infection associated with Escherichia coli: a multilevel model. J Antimicrob Chemother 67(10):25232530

29.Balslev U, Bremmelgaard A, Svejgaard E, Havstreym J, Westh H (2005) An outbreak of borderline oxacillin-resistant Staphylococcus aureus (BORSA) in a dermatological unit. Microb Drug Resist 11(1):78-81

30.Skinner S, Murray M, Walus T, Karlowsky JA (2009) Failure of cloxacillin in treatment of a patient with borderline oxacillin-resistant Staphylococcus aureus endocarditis. J Clin Microbiol 47(3):859-861

31.Nadarajah J, Lee MJ, Louie L, Jacob L, Simor AE, Louie M, McGavin MJ (2006) Identification of different clonal complexes and diverse amino acid substitutions in penicillin-binding protein 2 (PBP2) associated with borderline oxacillin resistance in Canadian Staphylococcus aureus isolates. J Med Microbiol 55(Pt 12):1675-1683

32. Mellmann A, Weniger T, Berssenbrügge C, Keckevoet U, Friedrich AW, Harmsen D, Grundmann $\mathrm{H}$ (2008) Characterization of clonal relatedness among the natural population of Staphylococcus aureus strains by using spa sequence typing and the BURP (based upon repeat patterns) algorithm. J Clin Microbiol 46(8):2805-2808

33.Grundmann H, Aanensen DM, van den Wijngaard CC, Spratt BG, Harmsen D, Friedrich AW; European Staphylococcal Reference Laboratory Working Group (2010) Geographic distribution of Staphylococcus aureus causing invasive infections in Europe: a molecularepidemiological analysis. PLoS Med 7(1):e1000215 
Donk, C.F.M. van der, Rijnders, M.I.A., Donker, G.A., Neeling, A.J. de, Nys, S., Stobberingh, E.Ef Is living in a border region a risk for a high prevalence of resistance? European Journal of Clinical Microbiology \& Infectious Diseases: 2013, 32(8), 989-995

\section{TABLES}

Table 1 Overview of the collected swabs and Staphylococcus aureus isolates

\begin{tabular}{llllll}
\hline Unit & GP-L & GP-NL & NH-L & NH-NL & Total \\
\hline No. of swabs & 1,096 & 1,595 & 291 & 1,060 & 4,042 \\
No. of isolates & 247 & 370 & 100 & 318 & 1,035 \\
Prevalence & $23 \%$ & $23 \%$ & $31 \%$ & $29 \%$ & $26 \%$ \\
No. of spa types & 130 & 163 & 39 & 114 & 329 \\
\hline
\end{tabular}

$G P-L$ general practice patients in the province of Limburg, GP-NL general practice patients in the remaining provinces of the Netherlands, $\mathrm{NH}-\mathrm{L}$ nursing home residents in the province of Limburg, $\mathrm{NH}-\mathrm{NL}$ nursing home residents in the remaining provinces of the Netherlands

Table 2 Antibiotic resistance among $S$. aureus isolates collected from general practice (GP) patients and nursing home (NH) residents

\begin{tabular}{lllll}
\hline Antimicrobial agent & GP-L (247) & GP-NL (348) & NH-L (100) & NH-NL (318) \\
\hline Oxacillin & $1 \%$ & $1 \%$ & $2 \%$ & $1 \%$ \\
Clarithromycin & $7 \%$ & $5 \%$ & $2 \%$ & $8 \%$ \\
Clindamycin & $1 \%$ & $0 \%$ & $0 \%$ & $2 \%$ \\
Ciprofloxacin & $1 \%$ & $2 \%$ & $24 \%$ & $34 \%$ \\
Fusidic acid & $6 \%$ & $6 \%$ & $6 \%$ & $2 \%$ \\
Tetracycline & $3 \%$ & $5 \%$ & $2 \%$ & $9 \% *$ \\
Trimethoprim-sulfamethoxazole & $0 \%$ & $0 \%$ & $0 \% *$ & $9 \%$ \\
\hline
\end{tabular}

$G P-L$ general practice patients in the province of Limburg, GP-NL general practice patients in the remaining provinces of the Netherlands, $N H-L$ nursing home residents in the province of Limburg, $\mathrm{NH}-\mathrm{NL}$ nursing home residents in the remaining provinces of the Netherlands

*Significant difference between the two groups of $\mathrm{NH}$ isolates 
Donk, C.F.M. van der, Rijnders, M.I.A., Donker, G.A., Neeling, A.J. de, Nys, S., Stobberingh, E.Ef Is living in a border region a risk for a high prevalence of resistance? European Journal of Clinical Microbiology \& Infectious Diseases: 2013, 32(8), 989-995

Table 3 Distribution of spa-clonal complexes (spa-CCs) among isolates collected from GP and NH patients

\begin{tabular}{|c|c|c|c|c|c|c|}
\hline spa-CC & Isolates (\%) & spa $(\%)$ & GP-L (\%) & GP-NL (\%) & NH-L (\%) & NH-NL (\%) \\
\hline spa-CC 012 & $299(30)$ & $100(30)$ & $73(30)$ & $110(32)$ & $29(29)$ & 87 (27) \\
\hline spa-CC 084 & $124(13)$ & $27(9)$ & $37(15)$ & 47 (14) & $18(18)^{*}$ & $22(7)^{*}$ \\
\hline spa-CC 002 & $105(10)$ & $26(8)$ & $19(8)$ & $26(7)$ & $5(5)^{*}$ & $55(17)^{*}$ \\
\hline spa-CC 024 & $126(12)$ & $19(6)$ & $15(6)$ & $25(7)$ & $23(23)$ & $63(20)$ \\
\hline spa-CC 078 & $36(4)$ & $19(6)$ & $17(7)$ & $14(4)$ & $1(1)$ & $4(1)$ \\
\hline spa-CC 127 & $66(7)$ & $18(5)$ & $12(5)$ & $26(7)$ & $6(6)$ & $22(7)$ \\
\hline spa-CC 166 & $35(3)$ & $15(5)$ & $11(4)$ & $15(4)$ & $0(0)$ & $9(3)$ \\
\hline spa-CC 005 & $30(3)$ & $13(4)$ & $5(2)$ & $14(4)$ & $2(2)$ & $9(3)$ \\
\hline spa-CC 159 & $17(2)$ & $10(3)$ & $7(3)$ & $9(3)$ & $0(0)$ & $1(0)$ \\
\hline spa-CC 216 & $27(3)$ & $8(2)$ & $7(3)$ & $4(1)$ & $1(1)$ & $15(5)$ \\
\hline spa-CC 160 & $12(1)$ & $6(2)$ & $6(2)$ & $5(1)$ & $0(0)$ & $1(0)$ \\
\hline spa-CC 364 & $9(1)$ & $4(1)$ & $4(2)$ & $4(1)$ & $0(0)$ & $1(0)$ \\
\hline spa-CC 1045 & $5(0)$ & $3(1)$ & $2(1)$ & $1(0)$ & $1(1)$ & $1(0)$ \\
\hline No founder 1 & $3(0)$ & $2(1)$ & $0(0)$ & $3(1)$ & $0(0)$ & $0(0)$ \\
\hline No founder 2 & $2(0)$ & $2(1)$ & $1(0)$ & $1(0)$ & $0(0)$ & $0(0)$ \\
\hline No founder 3 & $3(0)$ & $2(1)$ & $2(1)$ & $1(0)$ & $0(0)$ & $0(0)$ \\
\hline Singletons & $33(3)$ & $23(7)$ & $8(3)$ & $15(4)$ & $1(1)$ & $9(3)$ \\
\hline Excluded & $70(7)$ & $32(10)$ & $19(8)$ & $25(7)$ & $11(11)$ & $15(5)$ \\
\hline Not typable & $11(1)$ & $0(0)$ & $2(1)$ & $3(1)$ & $2(2)$ & $4(1)$ \\
\hline Total & 1,013 & 329 & 247 & 348 & 100 & 318 \\
\hline
\end{tabular}

$G P-L$ general practice patients in the province of Limburg, GP-NL general practice patients in the remaining provinces of the Netherlands, $N H-L$ nursing home residents in the province of Limburg, $\mathrm{NH}-\mathrm{NL}$ nursing home residents in the remaining provinces of the Netherlands

*Significant difference between the NH-L and NH-NL isolates 
Donk, C.F.M. van der, Rijnders, M.I.A., Donker, G.A., Neeling, A.J. de, Nys, S., Stobberingh, E.Ef Is living in a border region a risk for a high prevalence of resistance? European Journal of

Table 4 Composition of the spa-CCs

\begin{tabular}{|c|c|c|}
\hline spa-CC & spa types & MLST CC (ST) \\
\hline spa-CC 012 & $\begin{array}{l}\text { t004, t012, t015, t018, t019, t021, t031, t034, t037, t040, t050, t065, t069, t073, } \\
\text { t074, t095, t096, t102, t116, t122, t138, t230, t238, t266, t274, t275, t276, t300, t302, } \\
\text { t318, t331, t338, t370, t404, t406, t483, t505, t571, t576, t583, t589, t620, t630, t631, } \\
\text { t706, t740, t772, t822, t840, t861, t908, t937, t950, t1 130, t1149, t1238, t1239, t1281, } \\
\text { t1504, t1510, t1574, t1827, t1932, t2077, t2135, t2143, t2208, t2209, t2210, t2239, } \\
\text { t2254, t2269, t2275, t2387, t2479, t2489, t2496, t2539, t2540, t2541, t2544, t2548, } \\
\text { t2557, t2561, t2566, t2568, t2572, t2610, t2659, t2674, t2682, t2821, t2864, t4441, } \\
\text { t4905, t5834, t7110, t7126, t7143, t7147 }\end{array}$ & 30,45 \\
\hline spa-CC 084 & $\begin{array}{l}\mathrm{t} 084, \mathrm{t} 085, \mathrm{t} 091, \mathrm{t} 094, \mathrm{t} 252, \mathrm{t} 279, \mathrm{t} 346, \mathrm{t} 348, \mathrm{t} 360, \mathrm{t} 393, \mathrm{t} 491, \mathrm{t} 547, \mathrm{t} 774, \mathrm{t} 796, \mathrm{t} 853 \\
\mathrm{t} 867, \mathrm{t} 1243, \mathrm{t} 1363, \mathrm{t} 1716, \mathrm{t} 1943, \mathrm{t} 2074, \mathrm{t} 2543, \mathrm{t} 2556, \mathrm{t} 2567, \mathrm{t} 2616, \mathrm{t} 5875, \mathrm{t} 7134\end{array}$ & 7,15 \\
\hline spa-CC 002 & $\begin{array}{l}\mathrm{t} 001, \mathrm{t} 002, \mathrm{t} 010, \mathrm{t} 041, \mathrm{t} 062, \mathrm{t} 067, \mathrm{t} 179, \mathrm{t} 242, \mathrm{t} 306, \mathrm{t} 311, \mathrm{t} 389, \mathrm{t} 447, \mathrm{t} 509, \mathrm{t} 539, \mathrm{t} 548, \mathrm{t} 688, \\
\mathrm{t} 837, \mathrm{t} 1215, \mathrm{t} 1340, \mathrm{t} 2070, \mathrm{t} 2164, \mathrm{t} 2212, \mathrm{t} 2491, \mathrm{t} 2542, \mathrm{t} 2724, \mathrm{t} 6160\end{array}$ & 5 \\
\hline spa-CC 024 & $\begin{array}{l}\mathrm{t} 008, \mathrm{t} 024, \mathrm{t} 064, \mathrm{t} 104, \mathrm{t} 190, \mathrm{t} 197, \mathrm{t} 334, \mathrm{t} 377, \mathrm{t} 530, \mathrm{t} 648, \mathrm{t} 701, \mathrm{t} 711, \mathrm{t} 846, \mathrm{t} 1171 \\
\mathrm{t} 2041, \mathrm{t} 3060, \mathrm{t} 3802, \mathrm{t} 4299, \mathrm{t} 5279\end{array}$ & 8 \\
\hline spa-CC 078 & $\begin{array}{l}\mathrm{t} 056, \mathrm{t} 078, \mathrm{t} 081, \mathrm{t} 087, \mathrm{t} 150, \mathrm{t} 258, \mathrm{t} 353, \mathrm{t} 436, \mathrm{t} 469, \mathrm{t} 660, \mathrm{t} 775, \mathrm{t} 814, \mathrm{t} 1102 \\
\mathrm{t} 1312, \mathrm{t} 1541, \mathrm{t} 1671, \mathrm{t} 1898, \mathrm{t} 2039, \mathrm{t} 2078\end{array}$ & 25,101 \\
\hline spa-CC 127 & $\begin{array}{l}\mathrm{t} 114, \mathrm{t} 127, \mathrm{t} 177, \mathrm{t} 189, \mathrm{t} 224, \mathrm{t} 267, \mathrm{t} 286, \mathrm{t} 359, \mathrm{t} 376, \mathrm{t} 591, \mathrm{t} 1236, \mathrm{t} 1407, \mathrm{t} 1787, \mathrm{t} 2500, \\
\mathrm{t} 2569, \mathrm{t} 2612, \mathrm{t} 2819, \mathrm{t} 7123\end{array}$ & 1 \\
\hline spa-CC 166 & $\begin{array}{l}\mathrm{t} 089, \mathrm{t} 136, \mathrm{t} 153, \mathrm{t} 166, \mathrm{t} 240, \mathrm{t} 369, \mathrm{t} 884, \mathrm{t} 1014, \mathrm{t} 2038, \mathrm{t} 2071, \mathrm{t} 2073, \mathrm{t} 2080 \\
\mathrm{t} 2547, \mathrm{t} 2854, \mathrm{t} 7162\end{array}$ & \\
\hline spa-CC 005 & $\mathrm{t} 005, \mathrm{t} 060, \mathrm{t} 223, \mathrm{t} 474, \mathrm{t} 790, \mathrm{t} 1433, \mathrm{t} 1629, \mathrm{t} 2570, \mathrm{t} 2618, \mathrm{t} 2681, \mathrm{t} 5485, \mathrm{t} 5926, \mathrm{t} 7156$ & 22 \\
\hline spa-CC 159 & $\mathrm{t} 159, \mathrm{t} 171, \mathrm{t} 272, \mathrm{t} 284, \mathrm{t} 408, \mathrm{t} 645, \mathrm{t} 659, \mathrm{t} 738, \mathrm{t} 2213, \mathrm{t} 2820$ & 121 \\
\hline spa-CC 216 & $\mathrm{t} 172, \mathrm{t} 216, \mathrm{t} 471, \mathrm{t} 1293, \mathrm{t} 2079, \mathrm{t} 2488, \mathrm{t} 3527, \mathrm{t} 4303$ & 59 \\
\hline spa-CC 160 & $\mathrm{t} 156, \mathrm{t} 160, \mathrm{t} 213, \mathrm{t} 771, \mathrm{t} 1702, \mathrm{t} 3938$ & 12 \\
\hline spa-CC 364 & $\mathrm{t} 364, \mathrm{t} 493, \mathrm{t} 2492, \mathrm{t} 2680$ & \\
\hline spa-CC 1045 & $\mathrm{t} 099, \mathrm{t} 100, \mathrm{t} 1045$ & 9 \\
\hline No founder 1 & $\mathrm{t} 148, \mathrm{t} 2016$ & \\
\hline No founder 2 & $\mathrm{t} 186, \mathrm{t} 729$ & $(88)$ \\
\hline No founder 3 & $\mathrm{t} 246, \mathrm{t} 2495$ & \\
\hline \multirow[t]{4}{*}{ Singletons } & $\begin{array}{l}\mathrm{t} 106, \mathrm{t} 344, \mathrm{t} 587, \mathrm{t} 818, \mathrm{t} 878, \mathrm{t} 1362, \mathrm{t} 1406, \mathrm{t} 2050, \mathrm{t} 2075, \mathrm{t} 2076, \mathrm{t} 2490, \mathrm{t} 2494, \\
\mathrm{t} 2558, \mathrm{t} 2559, \mathrm{t} 2573, \mathrm{t} 2615, \mathrm{t} 2617, \mathrm{t} 5874, \mathrm{t} 7108, \mathrm{t} 7132\end{array}$ & $(20)$ \\
\hline & $\mathrm{t} 164$ & $(59)$ \\
\hline & t199 & $(109)$ \\
\hline & t209 & \\
\hline \multirow[t]{4}{*}{ Excluded } & $\begin{array}{l}\mathrm{t} 059, \mathrm{t} 118, \mathrm{t} 287, \mathrm{t} 362, \mathrm{t} 502, \mathrm{t} 524, \mathrm{t} 535, \mathrm{t} 605, \mathrm{t} 643, \mathrm{t} 808, \mathrm{t} 929, \mathrm{t} 1152, \\
\mathrm{t} 1200, \mathrm{t} 1209, \mathrm{t} 1456, \mathrm{t} 1509, \mathrm{t} 2176, \mathrm{t} 2207, \mathrm{t} 2211, \mathrm{t} 2246, \mathrm{t} 2365, \mathrm{t} 2383, \\
\mathrm{t} 2493, \mathrm{t} 2571, \mathrm{t} 2611, \mathrm{t} 2613, \mathrm{t} 2614, \mathrm{t} 2853, \mathrm{t} 4386\end{array}$ & \\
\hline & t026 & 45 \\
\hline & $\mathrm{t} 233$ & $(59)$ \\
\hline & $\mathrm{t} 386$ & (1) \\
\hline
\end{tabular}

Overview of the spa types in every spa-CC and the associated MLST clonal complex (CC) or sequence type (ST), associated via the Ridom SpaServer 